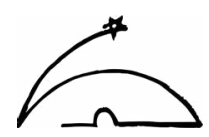

\title{
Apresentação
}

\section{Desenvolvimento e populações indígenas}

\author{
João Roberto Bort Jr. ${ }^{1}$ \\ Arianne Rayis Lovo ${ }^{2}$
}

Depois de longa e difícil mobilização para a admissão do sistema de cotas étnico-raciais pelo Conselho Universitário da Universidade Estadual de Campinas (Unicamp), chegaram à instituição, em 2019, os primeiros graduandos indígenas selecionados por vestibular. Se a conquista é imprescindível devido à sua natureza política, porque procura reverter estabelecidas formas de manutenção de desigualdades entre negros, brancos e índios, ela também é urgente por razões epistemológicas, no sentido de que os ameríndios ingressantes, com seus saberes tradicionais, certamente, indigenizarão a comunidade científica que, ao contrário de sua denominação, tem sido pouco universal no que diz respeito à incorporação e ao fomento de pensamentos Outros que convivem na sociedade brasileira. Essa posição foi claramente explicada por Ailton Krenak durante sua comunicação numa mesa-redonda sobre presença indígena na universidade, ocorrida no Instituto de Economia da Universidade Estadual de Campinas (Unicamp) em novembro de 2018. De forma perspicaz, Krenak recolocou o problema de modo mais amplo, destacando - como se pode conferir na sua fala que antecede este dossiê - que a questão é o lugar mal resolvido dos indígenas em nosso país. Sua análise ainda demonstra como isso se correlaciona aos projetos ocidentais de vida e morte para outras existências não humanas e humanas, entre as quais estão os indígenas. Em razão de uma lógica de mercado a partir da qual tudo e todos são passíveis de mensuração e metrificação, alguns, após definidos seus valores utilitários, poderiam ser extinguidos, porque pouco ou nada oferecem em termos de recursos à produção econômica, e outros, pelo seu inverso significativo, deveriam ser consumidos predatoriamente.

Se acrescentarmos as reflexões de Nodari (2014: 7) sobre o consumo capitalista, veremos que esse fez, todavia, o " "projeto humano" tornar-se "a sombra de seu lixo". Nessa metafísica da utilidade, a devoração inicia-se, primeiramente, pela redução métrico-simbólica do que é relacional, intenso e potente de sentido no mundo a contidas, limitadas e circunscritas dimensões instrumentais, e, por consequência, seus excessos, o que está fora da delimitação conceitual de útil, passam a ser indigestos e viram lixo. Com isso, se toda digestão é um processo de transformação recíproca do que é comido e de quem come, então não parecem estranhas as similitudes produzidas no capitalismo entre devires de uma parcela dos humanos e de coisas tornadas rejeitos.

Pensando a inflexão desse princípio criador de utilidades sobre pessoas, Ailton Krenak

1 Doutorando em Antropologia Social pela Universidade Estadual de Campinas (Unicamp).

2 Doutoranda em Antropologia Social pela Universidade Estadual de Campinas (Unicamp). 
afirma que os indígenas, mantidas suas diferenças em relação à civilização, nada teriam a contribuir e, com isso, deveriam seguir o mesmo destino das coisas ou permanecer vivendo distantes nas paisagens naturais a que estão associados em nosso imaginário nacional. Senão, para que pudessem servir à sociedade colonizadora, ou à universidade, por exemplo, que extinguidas fossem suas particularidades culturais. A aposta de Krenak é a de que, provavelmente, seremos capazes de redefinir nossas posições epistemológicas, que informam nossos espaços acadêmico-científicos acerca dos saberes que são válidos, se fizermos uma releitura ontológica da separação entre natureza e cultura. Precisaríamos recolocar os sentidos da vida e, para tanto, seria preciso ressignificar, por um lado, a compreensão e a formação de sujeitos - que não fossem vistos como tábulas rasas nascidas para serem orientadas à visão produtivista, mas que fossem levados à percepção do conjunto das interrelações que há entre entes vivos e não vivos -, exigindo de nós, por outro lado, uma revisão das noções sobre existir. Um programa educacional para o qual os ameríndios têm muito a oferecer e que viria a ser, se acrescentarmos novamente o que pensa Nodari (2014), "uma ferramenta política fundamental" (Ibid.: 17) para "consumir o consumo", i.e., "uma digestão desse processo, a sua dissolução e transformação em algo outro" (Ibid.: 4).

É exatamente essa crítica que nos impele trazer a público o dossiê Desenvolvimento e populações indigenas, que procura oferecer novas possibilidades interpretativas sobre a noção de "desenvolvimento" a partir de sugestões advindas de experiências e pontos de vista ameríndios. Desse modo, é possível afirmar que há uma organicidade temática neste volume da revista que transcende o próprio dossiê e que igualmente justifica a subversão de nossa apresentação, iniciada pelo que vem antes, o motivador de sua organização e, sendo assim, a ele relacionado. Até mesmo porque, conferirão na leitura dos textos, Ailton Krenak sempre volta, posto que é um ator há muito tempo conhecido por limitar as práticas que intencionam criar condições mais perfeitas para o pleno desenvolvimento de setores produtivos da sociedade brasileira. Embora não componha o dossiê, o relato da realizadora cultural Jade Rainho sobre uma outra versão das denúncias indígenas às catástrofes da mineração, realizada por uma rezadeira guarani-kaiowá que nos lembra da agência do Curupira irado, merece atenção necessária para que o entendimento se complete.

Os projetos de cunho desenvolvimentista que se caracterizam pelo acúmulo e lucro privado ou individual têm levado a efeito a expansão do capital global e nacional, mas sem deixar de implicar problemas e modificações de ordem econômica, social e política aos povos ditos tradicionais, contudo, com exceção do estudo sobre as consequências do projeto de transposição do Rio São Francisco, a presente publicação trata privilegiadamente de indígenas em razão de interesses de pesquisa mais estreitos ${ }^{3}$. Ao final do volume temático certamente ficará compreensível como maneiras de pensar e gerir desenvolvimentos infletem sobre povos ameríndios, bem como estarão evidentes alguns de seus modos criativos de buscarem ativamente negociar e garantir suas

3 Os pesquisadores associados à empreitada da editoração da revista Maloca e da publicação deste dossiê realizam pesquisas junto a populações ameríndias e estão associados ao Centro de Pesquisa em Etnologia Indígena (CPEI) da Universidade Estadual de Campinas (UNICAMP), logo possuem interesses centrais em estudos que tratem desses povos. 
autonomias, seus direitos, vidas, bem como de continuar, com interesses maiores ou menores, certas estruturas que estejam sob riscos de serem alteradas ou interditas. São suas particulares organizações e produções de si e de suas relações com outras existências - esses muitos Outros que vão, nos casos que inspiram as descrições aqui reunidas, de parentes e "espíritos" a ambientes e rios - que oferecem resistências e possibilidades de imaginar e agir diferentemente do que tem sido feito pelo mundo ocidental em relação ao futuro. A diversidade sociocosmológica indígena, fundamentada em pressupostos ontológicos e, por isso, relacionais distintos daqueles que informam as sociedades que constroem projetos de desenvolvimento e aparatos estatais para os sustentar, são imprescindíveis experiências para se ponderar equívocos na efetivação de instrumentos legais ou práticos que vêm embasando ambicionadas tentativas de melhorar a vida segundo uma lógica produtivista ou mercantil.

Todos os artigos publicados permitem essa conclusão mais geral, inclusive as já citadas contribuições de Ailton Krenak e de Jade Rainho. Coube a cada autora ou autor do dossiê trazer da Amazônia e das regiões Nordeste e Centro-Sul do Brasil os dados etnográficos que mostram as ponderações críticas dos indígenas acerca de vias desenvolvimentistas praticadas, até mesmo as mais sustentáveis, como ensaia Alcida Rita Ramos no artigo de abertura.

Baseada principalmente em quatro pesquisas sobre povos amazônicos, o trabalho de Alcida Ramos, Desenvolvimento rima com encantamento, informa-nos sobre a inoperância de noções ortodoxas de "desenvolvimento" quando vistas à luz das escolhas indígenas sobre o viver e de suas diferenças socioculturais, o que já foi considerado, como lembra a autora, por membros de povos da Nicarágua, Bolívia e Brasil. A crença no "progresso" e no "desenvolvimento", concepções irmãs forjadas no processo de racionalização científica, mesmo diante de seus efeitos malfadados por muitos lugares, indica que a constituição da modernidade não significou desencantamento do mundo, mas o seu reencantamento com a substituição do objeto de nossa fé. Distintamente, os indígenas têm formulado antídotos aos desastres que se originam das atividades de brancos que geram palavras, coisas e ações.

Aos projetos que visam o avanço econômico, os ameríndios têm introduzido suas formas particulares de resolução, como, conforme exemplo, os Baniwa que se utilizam de conhecimentos obtidos do período das missões salesianas no Noroeste Amazônico para formularem projetos que possuem interesses ligados à saúde, ao território, à educação e à autossustentação. São possibilidades de redistribuição de bens, inclusive os que foram deixados por eles próprios aos brancos no tempo mítico. Nesse sentido, esforços de melhoria de vida passam ao largo de visões de enriquecimento pessoal. No caso dos Makuna do lado colombiano da região do Uaupés, a tradução de saberes cosmopolíticos em planos de gestão territorial, mesmo que essencializadora por vezes, e o aproveitamento de incongruências na legislação sobre os territórios étnicos foram fundamentais para efetivação da autonomia e da recuperação de espaços. Os Ashaninka adotaram a ideologia do "índio ecológico" nas atividades da cooperativa montada e dirigida por um chefe estruturalmente mais central, que sabe favorecer-se, semelhantemente aos demais exemplos, de conhecimentos 
exteriores para manter a reprodução físico-cultural do povo por meio de relações com o mercado. Apesar da posição do líder ter formado relações verticalizadas de produção e detenção de bens entre eles, não quer dizer que não se questionem sobre a regra que deveria organizar a circulação de riquezas. Os Ye'kuana, por sua vez, evitam relações com o mercado que lhes coloquem condições à realização de sua produção e, como empreendedores que seguem sem uma cooperativa, adquirem dinheiro para incrementar a vida por meio do acúmulo dos saberes dispersos no mundo, sendo a maneira pela qual estão realizando a profecia de wätunnä, fonte de suas certezas sobre serem os próximos donos do poder. Praticando métodos ascéticos de empreender próximos aos dos brancos, os Ye'kuana recusam, entretanto, uma vertical e hierárquica apropriação de bens. As aprendizagens de saberes Outros, porém, os transforma: jovens que se entendem em condições de enfrentar os mais velhos matam-se ou ameaçam se matar.

Alcida Ramos verifica, ao final de seu artigo, recorrências em todos as situações analisadas e conclui, com destaque ao que é principal, que esses povos amazônicos anseiam o desenvolvimento desde que prossigam vivendo de acordo com seus critérios organizativos e sua cosmologia. Entre encantamentos que conhecem, preferem os seus mesmos. O intenso interesse por bens exteriores não tem sido causa de ruptura da redistribuição, visto que os introduzem na vida social através de circuitos de troca, assim como não tem gerado desigualdades, pois formulam formas de evitação, como a interessante feitiçaria entre os Baniwa e demais povos. Os equívocos ${ }^{4}$ resultantes do "mercado de projetos", demonstra a autora, surgem quando os saberes indígenas passam a instigar propostas de gerenciamento sustentável de recursos que, no entanto, não consideram entender a indissociabilidade entre os conhecimentos e os universos simbólicos a que estão ligados. As incompreensões aparecem da relação incompatível das atividades produtivas de caráter mercantil-industrial com elementos socioculturais desses povos, fazendo da horizontalidade e da dádiva problemas que os ameríndios precisam equacionar.

A propósito, um caso distante geograficamente do Noroeste e do Norte-Amazônico, em décadas atrás, apenas reforça as conclusões de Alcida Ramos. Quando a Companhia de Desenvolvimento dos Vales do São Francisco (CODEVASF) implantou, entre os anos de 1970-1980, produção cooperativista e irrigada de arroz no Baixo São Francisco (Alagoas) e incorporou os Kariri-Xocó como trabalhadores, uma vez que o projeto foi instalado em seu território tradicional, conflitos surgiram com os técnicos que pouco aceitavam os indígenas deixarem de cumprir com os horários estabelecidos de irrigação para irem aos rituais do Ouricuri (MATA, 1989).

Diante desses planos interculturais que chegam aos ameríndios - e, como se vê e verá adiante, não só na Amazônia -, um desafio, segundo Ramos, desenha-se: trata-se de garantir igualdade linguística, material e simbólica sob risco de serem constituídos lugares diferentes para os que se inter-relacionam.

4 Devem ser outros mais da "série de equívocos, nem sempre controlados, (parafraseando Viveiros de Castro [2004])", como sugere Novo neste dossiê. 
No artigo de Artionka Capiberibe, Um interminável Brasil colônia: os povos indígenas e um outro desenvolvimento, a dimensão conflitiva de equívocos entre indígenas, agentes sociais e estatais é ainda mais saliente. A antropóloga explora com vivacidade e potência analítica as estruturas históricas que marcam a atuação do aparelho administrativo estatal que deslegitima e subjuga os povos indígenas desde tempos coloniais até a contemporaneidade. Se, no Império, o interesse da Coroa estava voltado a explorar a mão-de-obra de populações negras e indígenas a fim de produzir bens agrícolas que atendia a uma demanda mercantilista europeia, nos dias atuais, esse modelo continua sendo reposto sob forma transformada em que, desta vez, são as inúmeras ações dos poderes públicos que tem na figura da terra indígena seu alvo principal.

A autora aponta que as mudanças climáticas e a exploração desenfreada dos recursos naturais, levado a cabo pela "ontologia mercantilista" e pela flexibilização dos licenciamentos ambientais, compõem parte da agenda política governamental negacionista, pois recusa a ciência e os inúmeros dados que demonstram um processo de irreversibilidade da possibilidade da vida na terra em momentos futuros. Frente a isso, os povos indígenas perfazem as suas lutas cosmopolíticas que se dá tanto pela palavra quanto pelo corpo, "agregando o corpo à fala". Se a palavra é uma ação no mundo, uma palavra/corpo é o movimento da ação que permite corpos indígenas serem livres, sendo a liberdade compreendida como uma ação que se faz coletiva e não individualmente. Com isso, Capiberibe ressalta que a visibilidade indígena, outrora privilegiada pela ação política e performática, é produzida também pelo corpo enquanto ação. Ou seja, os adornos e pinturas utilizadas nas ações ameríndias, como por exemplo a fala de Guajajara num show musical em 2017, ou a emblemática pintura de Ailton Krenak no Congresso Nacional em 1987, agem como instrumentos de comunicação com um Outro, ao mesmo tempo em que operam como mecanismo de proteção a ele próprio. Essa dupla valência permite o confronto de ontologias distintas, sendo que as indígenas, entretanto, têm procurado efetuar acordos pragmáticos através de possíveis diálogos e alianças com a não indígena.

Marina Novo, em seu texto As políticas de transferência de renda e o desenvolvimento: o caso dos Kalapalo do Alto Xingu, apresenta como o Programa Bolsa Família (PBF) atinge de diferentes formas a vida dos Kalapalo que vivem no Território Indígena do Xingu (TIX), no estado do Mato Grosso. Trabalhando há mais de dez anos junto a esse povo, Novo constrói um texto conciso e instigante, mostrando como os Kalapalo desafiam a lógica da propriedade particular e dos direitos individuais. O argumento central da autora é explicitar as ambivalências existentes nas políticas de transferência de renda e seus "equívocos", conceito que toma emprestado de Viveiros de Castro e que evidencia o confronto de lógicas de produção e de parentesco entre os Kalapalo e o Estado. Assim, conceitos como "família" e "pobreza" são dois termos centrais utilizados para as políticas de distribuição de renda que podem ser lidos a partir desses "equívocos".

A noção de família utilizada pelo Cadastro único do PBF se difere daquela entendida pelas famílias indígenas, em especial os povos amazônicos, como a autora aponta, pois nela há uma pluralidade de arranjos familiares que são baseados na convivialidade e em práticas de 
compartilhamento que não passam pela "dependência econômica". Novo ressalta que o cadastro elege como a responsável familiar uma mulher, e nem sempre isso é uma escolha prática entre os Kalapalo, pois, se comparadas aos homens, elas pouco dirigem-se às cidades e compreendem ou falam o português. Dessa forma, enquanto o Estado define pobreza elencando critérios monetários, os Kalapalo identificam-na como situação em que a pessoa "não tem ninguém para cuidar dela", ou seja, seu sentido está em relação ao viver adequadamente entre parentes. Logo, ser pobre é interpretado no registro do cuidado, sendo aquele que carece de alguém que lhe supra essa necessidade. Portanto, entre os Kalapalo, não há acúmulo de dinheiro, mas circulação de bens e recursos que o dinheiro faz acessar. Obter as mercadorias está associado à realização dos desejos, pois aqueles que não conseguem suprir tal falta, correm risco de adoecimento e até mesmo de morte. Como pontua Novo, apesar das políticas de transferência de renda terem aumentado o desejo e o número de objetos industrializados nas aldeias, a circulação dessas mercadorias acontece diretamente relacionado aos modos de vida kalapalo de compartilhamento e troca. Como se pode ver, seria perfeitamente possível incluir esse caso alto xinguano como mais um dentre os trabalhados por Alcida Ramos. De acordo com as palavras dessa etnóloga, nesses contextos todos, o fascínio pelos bens e riquezas industrializados não "traz consigo uma mudança estrutural de perspectiva na relação de humanos com objetos”.

A quarta contribuição ao dossiê é de Carla Souza de Camargo. Em Reivindicando fluxos em contextos de desigualdade: os povos indígenas do sertão de Itaparica e a Transposição do rio São Francisco, Camargo aproxima-nos das grandes modificações causadas aos povos Tuxá, Pipipã, e Pankararu do Sertão Nordestino pela construção do Eixo Leste da Transposição do Rio São Francisco. O projeto, voltado à resolução de problemas socioeconômicos decorrentes da falta d'água, integrou o "panorama desenvolvimentista" do Estado brasileiro nos governos Lula e Dilma que intentava estimular crescimento econômico de regiões pouco atrativas ao capital por meio de investimentos em infraestrutura com consequente geração de emprego. Se, por um lado, essas políticas públicas renovaram as ações megalomaníacas praticadas pelos militares no período ditatorial, por outro lado, em quase nada alteraram as maneiras de implementação dos projetos e de construções das obras.

A construção da Usina Hidrelétrica de Itapacarica (UHE Luiz Gonzaga), a partir da década de 1980, provocou a submersão de territórios entre Bahia e Pernambuco, deixando 40 mil pessoas desalojadas, entre elas, o povo Tuxá que vivia num complexo de ilhas em torno da Ilha da Viúva dentro do Rio São Francisco. Eles foram reassentados numa área muito menor do que o acordado na época, sendo realocados em três territórios apartados e divididos em três grupos distintos. Camargo aponta que há uma relação direta entre essa hidrelétrica e o canal leste de Transposição, pois este retira água de uma represa contígua ao lago de Itaparica, construído artificialmente dentro da UHE. Tal empreendimento também provocou transformações socioculturais incomensuráveis entre os Pankararu devido à inundação das corredeiras de Itaparica na construção da barragem da UHE, atingindo as cachoeiras que eram, até então, a morada dos "encantados" e o signo fundamental 
do "segredo" do grupo. Três décadas depois, a autora verifica que os Pankararu dependem de caminhões-pipa para abastecerem suas casas na aldeia, pois não há bombeamento suficiente para toda a população da TI Pankararu.

Essa mudança na organização social também ocorreu com os Pipipã, população que habita a $50 \mathrm{~km}$ do lago de Itaparica e que vivencia uma situação de sobreposição territorial em quatro extratos sobrepostos: uma reserva biológica (REBIO), um assentamento de Reforma Agrária administrado pelo Instituto Nacional de Colonização e Reforma Agrária (INCRA), um território reivindicado pelas etnias Kabiwá e Pipipã e uma área de construção de parte do trecho do canal Leste da Transposição do São Francisco. No entanto, mesmo com a promessa de uma oferta maior de água, a população local foi contra o projeto da transposição alegando que a água não serve para o consumo, e apontando que as únicas fontes de água doce de áreas próximas à aldeia, como Serra Negra, secaram com as frequentes dinamitações para a construção do canal.

Com esses "empreendimentos", Camargo enfatiza que as comunidades tradicionais de Itaparica perderam tanto o livre acesso a água quanto as técnicas tradicionais de manejo nos diferentes fluxos do rio. Nesse aspecto, ela ressalta que a palavra "empreendimento" adquire sentidos diversos entre os agentes envolvidos. Àqueles que defendem uma "ontologia mercantilista", para tomarmos de empréstimo a expressão utilizada por Capiberibe e que ilumina os desdobramentos desses projetos desenvolvimentistas, a construção do canal de transposição faz parte de um programa que trará "água a quem tem sede". No entanto, aos que vivem próximos do rio São Francisco, tal palavra corresponde às transformações profundas em seus modos de existência, evidenciando que tais obras foram pensadas sem consulta prévia às populações locais.

Frente a isso, a ação coletiva dos grupos envolvidos se faz por uma "luta indígena" que tem a resistência como estratégica histórica e marca a trajetória das lideranças indígenas no sertão de Itaparica, como as que compõem a APOINME (Articulação dos Povos Indígenas do Nordeste, Minas Gerais e Espírito) e o Comitê Especial Indígena formado dentro do Comitê da Bacia Hidrográfica do São Francisco (CBHSF), e que confrontam o projeto da transposição. Nesse aspecto, água e terra são dois polos não excludentes dessa ação política, pois a reivindicação por terra se dá, em grande medida, a partir das implicações sociais e políticas da construção da transposição do rio, que ao mudar o curso e os fluxos das águas, provoca uma modificação da organização social e um rearranjo das relações desses povos.

As pedagogas Beatriz Sales da Silva e Maria Teresa Eglér Mantoan apresentam práticas educacionais dos Xucuru-Kariri que vivem em Caldas, no estado de Minas Gerais, no artigo intitulado O aluno agregado - ou a presença de alguém que é, sem ser, na Escola Indígena Xucuru Kariri Warkanã de Aruanã, Caldas, MG. Apesar de não inserirem explicitamente a discussão que trazem sobre o cotidiano escolar desses indígenas junto à problemática do desenvolvimento, as autoras deixam notar que os Xucuru-Kariri recusam boa parte da forma e do conteúdo do currículo das escolas da cidade e, quase que inteiramente, a vivência de seus filhos no contexto urbano. Ou seja, em postura bastante aproximável a de outros ameríndios, os Xucuru-Kariri realizam algo 
como uma "domesticação" (ALBERT e RAMOS, 2002) da instituição escola, ou diríamos sua adequação aos seus valores e ideais de organização social e vida na aldeia, quando dela apropriam-se por reinvindicação junto à Superintendência Regional de Ensino de Poços de Caldas.

Quando Silva e Mantoan recorrem a transcrições de dez fragmentos de "mônadas" xucuru-kariri - também ditas "histórias narradas" em que se identifica, segundo definição benjamimiana, "memória", "rememoração" e "sentidos livres, múltiplos, historicamente construídos" -, as pesquisadoras permitem que observemos os Xucuru-Kariri de Caldas produzindo depoimentos sobre "as práticas educacionais" que são o objeto do artigo. Logo, o método expositivo priorizado deixa entrever todas as outras noções que se ligam à de escola, como, a título de exemplo, as de criança, aprendizagem, vida e experiência familiar, modos Outros de educar... Ao final de extensas narrativas ou "mônadas", as pedagogas argumentam que o processo educativo da aldeia rejeita formas de exclusão, porque desenvolvem uma espécie de subversão da restrita classificação dos estudantes em classes e séries por critério etário, a saber, aceitam a presença de alunos de outras turmas e sem matrícula nas salas de aula, os chamados "agregados". Concluem, então, dizendo que os Xucuru-Kariri implementam na prática cotidiana uma "escola hospitaleira".

Ao que nos parece, visto o apontamento de uma indígena sobre "agregado" ser um "termo que veio da Secretaria" e que o conheceu em "Minas", os Xucuru-Kariri, provavelmente depois de terem aprendido a significativa importância da matrícula e da categorização classe-serial na gestão escolar do Estado, passaram a aceitar uma nova categoria de aluno com o intuito de que seus modos de educar as crianças fossem aceitáveis. Aparentemente, os indígenas não precisavam dizer nada muito além sobre o fato de seus filhos, primos e irmãos quererem os acompanhar às aulas ("viu o irmão indo e queria ir junto, ficava lá"). Porém, diante de um Estado que parte seus atos administrativos da pressuposição de que relações pedagógicas não se interpenetram às parentais, esses índios não parecem ver problema algum em confirmarem que são "hospitaleiros". Com isso, aparentam esclarecer a uma maneira meio weberiana (WEBER, 1999) que o fundo da lógica da administração estatal é uma racionalização burocrática fundada na impessoalidade que, diante da educação que praticam, exige um nome ao que não tem registro e lugar na regulamentação instituída. Há, assim, um jeito diferenciado dos Xucuru-Kariri lidarem com os projetos que trazem de Poços de Caldas após exigir o direito à educação.

Se há dúvidas sobre os motivos que colocam o texto Do Porão à Primavera: história da antropologia no Brasil e protagonismo político no acervo da Associação Brasileira de Antropologia ao lado dos demais artigos deste dossiê - haja vista a pretensão de divulgar o acervo da Associação Brasileira de Antropologia (ABA) sob guarda do Arquivo Edgard Leuenroth (AEL- Unicamp) -, Thaís Farias Lassali, Amanda Gonçalves Serafim e Christiano Key Tambascia esclarecem-nas quando argumentam sobre sua relevância e descrevem o trabalho de organização e categorização dos documentos que o compõem. Ao afirmarem que nessas fontes documentais podemos resgatar histórias de atuações das diretorias da ABA e de antropólogos e antropólogas 
em importantes processos e debates político-econômicos da sociedade brasileira, envolvendo também comunidades tradicionais, acabam por mostrar campos de pesquisa que muito interessam aos estudiosos dos indígenas das Terras Baixas da América do Sul.

No acervo são encontradas, conforme informam, relatórios, tratativas, cartas e estudos produzidos pela associação e por órgãos do Estado e da sociedade civil, do país e do exterior, e que foram remetidos entre si. É importante notar que são possíveis acessos à parte da história da Antropologia que esteve vinculada politicamente à luta pelos direitos de diversas populações, obviamente também em favor de grupos indígenas. Nesse momento em que assistimos ao recrudescimento do conservadorismo com a ascensão da extrema-direita ao Poder, é provável que tal acervo forneça oportunidades de mais descrições tanto sobre a ligação histórica entre interesses político-econômicos e processos de avanços e retrocessos da cidadania quanto sobre continuidades e transformações do modelo de Estado predador-exploratório, para lembrarmos as questões às quais se dedica Artionka Capiberibe em seu texto. Lassali, Serafim e Tambascia informam haver a categoria de documentos "Projetos de desenvolvimento nacional", dentro da qual se encontram, por exemplo, dados sobre os Projetos Carajá, Calha Norte e Polonoroeste. Cremos também que é nesse grupo de documentações que podem estar localizadas condições para dar sequência à análise de Carla Souza de Camargo sobre as recentes e relativamente renovadas ações estatais de implementação de planos desenvolvimentistas no sertão ameríndio do Nordeste. Devem auxiliar no aprofundamento ainda maior das descrições sobre as conexões entre essas atuais e antigas políticas em termos de consequências para territórios e reproduções de povos indígenas, que sabiam, bem antes dos antropólogos, sobre as tais relações por tê-las experenciado.

O trio de pesquisadores demonstra que, para além do tema do desenvolvimento, há categorias de documentação para quem se debruça sobre problemáticas correlatas de investigação, como a de conflitos, territórios, parques e áreas indígenas. Em suma, todos os envolvidos na organização do fundo da ABA, como faz perceber a defesa por "uma etnografia desse arquivo", contribuíram à criação de possibilidades de pesquisa acerca de como a história - não só das políticas desenvolvimentistas - infletiu sobre indígenas e como ocorreu seu reverso recíproco. Trata-se de um trabalho, para os estudiosos das questões ameríndias, de alargamento do já enorme caminho aberto por Guia de fontes para a História Indigena e do Indigenismo em arquivos brasileiros (MONTEIRO, 1994), pois viabiliza um pouco mais as chances de "dar aos índios um novo lugar em nossa história" (ALMEIDA, 2015: 4) e de, com isso, seguindo as palavras de Krenak naquela mesa-redonda, iluminar essa "coisa tão mal resolvida" que é a "presença dos povos indígenas na sociedade brasileira". 


\section{Referências bibliográficas}

ALBERT, Bruce e RAMOS, Alcida. Pacificando o branco: cosmologias do contato no Norte-Amazônico. São Paulo: Unesp, 2000

ALMEIDA, Maria Regina Celestino de. "O lugar dos índios na história: a contribuição de John Monteiro". Fronteiras \& debates, vol. 2, n. 1, p. 3-4, jan. - jun. 2015.

NODARI, Alexandre. "Limitar o limite: modos de subsistência". Trabalho apresentado no seminário Os mil Nomes de Gaia: do Antropoceno à Idade da Terra. Rio de Janeiro - RJ, 2014. Disponível em https://osmilnomesdegaia.files.wordpress.com/2014/11/alexandre-nodari.pdf.

MATA, Verá Lúcia Calheiros. A semente da terra: identidade e conquista territorial por um grupo indigena integrado. Tese (Doutorado em Antropologia Social) - PPGAS, MN/UFRJ, Rio de Janeiro-RJ, 1989.

MONTEIRO, John Manuel (Org). Guia de fontes para a História Indígena e do Indigenismo em arquivos brasileiros: acervo das capitais. São Paulo: Núcleo de História Indígena e do Indigenismo da Universidade de São Paulo/ Fapesp, 1994.

VIVEIROS DE CASTRO, E. Perspectival anthropology and the method of controlled equivocation. Tipiti: Journal of the Society for the Anthropology of Lowland South America, v. 2, n. 1, p. 2-22, 2004.

WEBER, M. Economia e sociedade: fundamentos da sociologia compreensiva. Brasília, DF: UnB; São Paulo: Imprensa Oficial do Estado de São Paulo, 1999

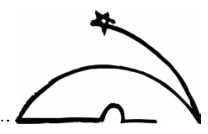

